\title{
A ORDEM METACONSTITUCIONAL DE DIREITOS HUMANOS E SEUS DESAFIOS NO MUNDO GLOBALIZADO
}

\section{THE METACONSTITUTIONAL ORDER OF HUMAN RIGHTS AND THEIR CHALLENGES IN THE GLOBALIZED WORLD}

\section{Guilherme Sandoval Góes*}

Resumo: $O$ presente trabalho tem por objetivo analisar as perspectivas de implantação de uma ordem metaconstitucional de direitos humanos, na qual o regime jurídico de proteção dos direitos fundamentais transcende as fronteiras do estado soberano. Para tanto, é necessário investigar os impactos do fenômeno da globalização neodarwinista que se projetam sobre a formação de uma ordem universal kantiana de direitos cosmopolitas. É nesse sentido que o presente trabalho pretende demonstrar que a proteção dos direitos humanos no mundo globalizado caminha entre duas grandes perspectivas autoexcludentes, quais sejam, de um lado, o projeto epistemológico neoliberal da ordem unipolar americana e, do outro, o projeto epistemológico metaconstitucional da ordem mundial multipolar. Em consequência, é importante examinar os desafios que o mundo globalizado apresenta à formação de uma ordem metaconstitucional de direitos humanos inspirada na força normativa do direito cosmopolítico kantiano de curso universal.

Palavras-chave: Estado Universal de Direito. Pax Americana. Metaconstitucionalismo.

Abstract: The present work aims to analyze the prospects for the implementation of a metaconstitutional order of human rights, in which the legal regime for the protection of fundamental rights transcends the borders of the sovereign state. To do so, it is necessary to investigate the impacts of the phenomenon of neo-Darwinian globalization that are projected on the formation of a Kantian universal order of cosmopolitan rights. It is in this sense that the present work intends to demonstrate that the protection of human rights in the globalized world walks between two great perspectives that are mutually exclusive, namely, on the one hand, the neoliberal epistemological project of the American unipolar order and, on the other, the metaconstitutional epistemological project of multipolar world order. As a consequence, it is important to examine the challenges that the globalized world presents to the formation of a metaconstitutional order of human rights inspired by the normative force of Kantian cosmopolitan law of universal course.

Keywords: Universal Rule of Law. Pax Americana. Metaconstitucionalism.

\footnotetext{
*Pesquisador do Programa Produtividade da UNESA. Pós-Doutorando em Geopolítica, Cultura e Direito pela UNIFA. Doutor e Mestre em Direito pela UERJ. Professor Emérito da ECEME. Membro do PPGCA da UNIFA e PPGSID da ESG. Professor de Direito Constitucional da EMERJ, UNESA e UCAM. Diplomado pelo Naval War College dos Estados Unidos da América (Newport, Rhode Island). Chefe da Divisão de Geopolítica e Relações Internacionais da ESG.
} 


\section{INTRODUÇÃO TEMÁTICA}

Em tempos de constitucionalismo pós-moderno, um dos grandes desafios do Estado Democrático de Direito é deslocar para a centralidade da teoria dos direitos fundamentais o regime jurídico de proteção internacional dos direitos humanos, dentro de uma perspectiva metaconstitucional (máxime com a consolidação dos tratados internacionais sobre direitos humanos).

Com efeito, a evolução da ciência jurídica perpassa necessariamente pelo aperfeiçoamento da proteção universal de direitos humanos, que deve se mover na direção de um marco legal mais sofisticado e que seja coerente - a um só tempo com a normatividade internacional e o sentimento constitucional de justiça. É nesse sentido que o presente trabalho, desenvolvido dentro do programa produtividade da Universidade Estácio de Sá, cujo tema era "Diálogos epistemológicos entre o Controle de Convencionalidade e o Controle de Constitucionalidade: desafios do Estado Neoconstitucional de Direito", tem a pretensão de examinar o fenômeno da globalização e seus impactos sobre o sistema de proteção dos direitos humanos.

Tal abordagem tem como eixo o exame do encontro epistemológico entre a globalização neodarwinista ${ }^{1}$, a geopolítica mundial e o direito constitucional, dentro de uma simbiose capaz de viabilizar a formação de uma ordem metaconstitucional dos direitos humanos. Ou seja, colima-se examinar o mundo pós-guerra Fria e seus impactos na ordem constitucional dos Estados subdesenvolvidos de modernidade tardia, com desiderato de encontrar um paradigma jurídico de universalização de direitos.

De fato, um dos grandes desafios do Estado Democrático de Direito do assim chamado Sul Global é a concepção de arquétipos constitucionais autóctones capazes de romper com o ciclo do empobrecimento estatal, garantindo dessarte vida digna para todos os seus cidadãos².

\footnotetext{
${ }^{1}$ A complexa mundialidade pós-Guerra Fria traz no seu imo a globalização neoliberal de neutralização axiológica da Constituição-Dirigente em prol de uma competição internacional neodarwinista acirrada entre centros mundiais de poder (EUA, China, União Europeia e Japão) e cuja materialização somente é possível com a mitigação ou até mesmo desconstrução total do Estado Democrático Social de Direito (Welfare State) no âmbito dos países de modernidade tardia (nações subdesenvolvidas da periferia do sistema internacional).

${ }^{2}$ Com efeito, o fim da Guerra Fria, em 1989, trouxe efeitos nocivos em relação às nações da África, América Central e Latina e a maior parte da Ásia, que são coletivamente conhecidas como o Sul
} 
Como se verá ao longo do presente artigo, a imposição de uma ordem metaconstitucional de direitos humanos na era globalizada somente ganhará concretude com a superação do paradigma tradicional do mundo unipolar neoliberal, de pax americana, controlado pelos países capitalistas desenvolvidos.

É nesse diapasão que se pode afirmar que o regime jurídico de proteção dos direitos humanos caminha entre duas grandes perspectivas que se contrapõem entre si, quais sejam, de um lado, o projeto globalizante do Estado Neoliberal de Direito e, do outro, o projeto cosmopolita do Metaconstitucionalismo do Estado Universal de Direito. Com tal tipo de intelecção em mente, será possível compreender as imbricações benéficas e nocivas entre a geopolítica hegemônica de poder da Pax Americana e o Estado Neoliberal de Direito, bem como a conexão entre a geopolítica multipolar de poder e o Estado Metaconstitucional de Direito.

A ideia de Pax Americana, como bem destaca Vicente de Paulo Barreto, é associada ao termo "globalização", in verbis.

1.1 O termo "globalização" foi, também, associado a um projeto sociopolítico, a Pax Americana, que após a queda do Muro de Berlim, foi considerado como hegemônico. O projeto, tanto para alguns teóricos, como na prática das relações financeiras, passou a ser considerado como qualitativamente superior aos demais modelos de regimes políticos, econômicos e sociais, encontrados nas diferentes nações do planeta. (BARRETO, 2010, p. 215-216)

Nesse sentido, observe, com atenção, que a visão de Pax Americana projeta a um só tempo, a imagem de declínio do "welfarismo constitucional", da desconstrução de direitos sociais e da vitória retumbante da democracia liberal. Com isso, o sistema jurídico-constitucional neoliberal passa a ser instrumentalizado pela redução jurídica do Estado, elemento central da desregulamentação normativa necessária à expansão do livre mercado mundial, bem como da relativização do conceito de soberania nacional. ${ }^{3}$

Global. Infelizmente, a situação desses países subdesenvolvidos do Sul Global projeta um quadro paradoxal que pode tanto gerar desenvolvimento econômico e social quanto agravar ainda mais a pobreza, a degradação ambiental, a fome e a violação dos direitos humanos do Sul Global, ao contrário do Centro Global, formado pelos países ricos que controlam o processo de tomada de decisões do sistema internacional.

${ }^{3}$ Nos últimos tempos, a discussão em torno dessas relações se há intensificado, especialmente a partir da tentativa de reconfiguração neoliberal do Estado, cuja proposta metodológico-científica 
Trata-se de um esforço de desconstrução do dirigismo constitucional, com o desiderato de retomar o arquétipo constitucional pré-weimariano de cunho absenteísta e individualista. Realmente, com o fim da Guerra Fria, surge a tendência de adoção desse modelo pré-weimariano, vale explicitar, o modelo liberal que existia antes da Constituição de Weimar, de 1919, na Alemanha, símbolo da democracia welfarista. ${ }^{4}$

Com rigor, o que se quer aqui demonstrar é que a queda do muro de Berlim, em 1989, simboliza o ponto de inflexão da efetividade dos direitos sociais, na medida em que a ordem liberal estabelece $o$ arquétipo constitucional pré-weimariano, que se ocupa tão somente com a revalorização da primeira dimensão de direitos fundamentais, cuja natureza é predominantemente negativo-defensiva (direitos civis e políticos).

E mais: é objetivo do presente artigo mostrar que são as linhas mestras do projeto neoliberal atreladas ao paradigma unipolar de pax americana que agravam a efetividade dos direitos sociais fundamentais nos países de modernidade tardia do Sul Global, o que evidentemente também implica na mitigação do projeto epistemológico metaconstitucional de inspiração kantiana. Ou seja, em oposição ao direito cosmopolita de índole idealista preconizado por Kant, surge a pax americana, projeto neoliberal da única superpotência remanescente da Guerra Fria, cuja linha dominante propõe a abertura mundial do comércio a partir de marco jurídico liberalizante em escala planetária. ${ }^{5}$

Enfim, com tal tipo de intelecção em mente, pretende-se demonstrar que o estado da arte do regime jurídico de proteção dos direitos humanos se encontra em

restaura o modelo de estatalidade mínima com o objetivo de desregulamentar relações jurídicas privadas, relativizando o conceito de soberania.

${ }^{4}$ Isto significa dizer, por outras palavras, que o fim da Guerra Fria foi seguido pelo fim da competição entre o liberalismo capitalista e o intervencionismo welfarista, sendo certo afirmar que o perfil constitucional que se impôs em escala planetária não foi 0 do projeto epistemológico metaconstitucional, baseado no Estado Universal de Direito, mas, sim, o projeto epistemológico neoliberal, baseado no Estado Mínimo Absenteísta. Portanto, o resultado desse projeto de poder unilateral e neoliberal não poderia ser outro senão a criação de uma ordem civilizatória distorcida que enfraquece as tendências de proteção internacional dos direitos humanos.

${ }^{5} \mathrm{Em}$ outras palavras, os grandes desafios da concretização de um verdadeiro Estado Universal de Direito, garantidor de direitos universais cosmopolitas de inspiração kantiana, concentram-se no projeto neoliberal que patrocina a redução jurídica do Estado em prol da competividade e liberdade de negociar. Não se trata, aqui, de negar o conceito de soberania do Estado nacional, matéria amplamente debatida até mesmo pelo positivismo jurídico, mas, sim, a falta de um caminho científico que leve à proteção metaconstitucional dos direitos humanos a partir da jurisdição constitucional. 
transição entre o constitucionalismo garantista do Estado Neoliberal de Direito e o constitucionalismo cosmopolita do Estado Metaconstitucional de Direito, perpassando ao mesmo tempo pela transição da ordem unipolar de pax americana para a ordem mundial multipolar.

É por isso que, antes de examinar a formação da ordem metaconstitucional como último estágio do regime de proteção dos direitos humanos na era pósmoderna, é necessário, antes, investigar a ordem neoliberal da pax americana.

\section{ESTADO NEOLIBERAL DE DIREITO E PAX AMERICANA (MUNDO AMERICANO)}

O cenário jurídico-constitucional que circunscreve o Estado pós-Guerra Fria ainda se encontra, induvidosamente, em construção, mas, no entanto, já apresenta imbricações complexas de um mundo globalizado que, a um só tempo, é:
a) Geopoliticamente pós-bipolar; ${ }^{6}$
b) Filosoficamente pós-moderno;
c) Juridicamente pós-positivista;
d) Midiaticamente pós-verdadeiro;
e) Soberanamente pós-nacional;
f) Estadisticamente pós-welfarista.

De fato, vive-se a era da pós-bipolaridade geopolítica (colapso da União Soviética e fim da Guerra Fria), da era da pós-modernidade filosófica (fim dos ciclos liberal e social), da era do pós-positivismo jurídico (superação da aplicação positivista mecânica da lei), da era da pós-verdade (notícias criadas - fake news - suplantam as notícias verdadeiras), da era do Estado pós-nacional (relativização do conceito de soberania absoluta a partir do processo de globalização da economia) e da era da estatalidade pós-welfarista (crise do Estado Social ou Welfare State).

É nesse diapasão que destaca Luís Roberto Barroso (2003):

Planeta Terra. Início do século XXI. Ainda sem contato com outros mundos habitados. Entre a luz e sombra, descortina-se a pós-modernidade. 0 rótulo genérico abriga a mistura de estilos, a descrença no poder absoluto da razão, o desprestígio do Estado. A era da velocidade. A imagem acima do conteúdo. $O$ efêmero e o volátil parecem derrotar o permanente e 0 essencial. Vive-se a angústia do que não pôde ser e a perplexidade de um tempo sem verdades seguras. Uma época aparentemente pós-tudo: pósmarxista, pós-kelseniana, pós-freudiana. (BARROSO, 2003, p. 2)

\footnotetext{
${ }^{6}$ Mundo pós-bipolar significa o mundo do tempo presente, que surgiu com o fim da Guerra Fria e da bipolaridade geopolítica entre os EUA e a ex-URSS, daí a designação de mundo pós-bipolar.
} 
De tudo se vê, por conseguinte, a incrível velocidade da era pós-moderna que, em menos de duas décadas, já produziu três grandes momentos de ruptura paradigmática da História da Humanidade, a saber: a queda do muro de Berlim (1989), a queda das Torres Gêmeas (2001) e a crise financeira mundial (2008).

Tais eventos têm desdobramentos disruptivos para a ciência política e para o direito constitucional, na medida em que trazem no seu âmago as ideias de globalização da economia, abertura mundial do comércio, engenharia constitucional pré-weimariana, era de desregulamentação/descodificação, neutralização axiológica do dirigismo welfarista, relativização do conceito de soberania, redução jurídica do Estado, constitucionalismo garantista/absenteísta etc.

Com isso queremos dizer que o neoliberalismo de pax americana será o contraponto do metaconstitucionalismo da ordem mundial multipolar. Com a devida agudeza de espírito, o leitor haverá de captar o significado desse encontro epistemológico entre a mundialidade pós-moderna e seus desdobramentos no campo do direito constitucional, seja pela tentativa de neutralização axiológica da Constituição-Dirigente imposta pela vitória da democracia liberal e do capitalismo financeiro, seja pela tentativa de desregulamentação jurídico-constitucional capitaneada pela abertura mundial do comércio e pela relativização do conceito de soberania nacional. Como bem destacam Lenio Luiz Streck e José Luis Bolzan de Morais (2010):

\begin{abstract}
A globalização neoliberal já nasce autoritária, pois sua gênese explicita uma reação progressiva face aos efeitos da luta de classes desde a década de quarenta. (...) A tese da presença do Estado nas questões sociais (saúde, ensino, trabalho, etc.) é flagrante ruptura com o liberalismo clássico, contra o qual já se insurgira Keynes. (...) O que preocupava aquele que pode ser considerado o fundador do neoliberalismo, Friedrich Hayek, era exatamente o avanço das lutas políticas sindicais e os compromissos advindos do Welfare State com as classes trabalhadoras. (...) A ideia de privatização, carro chefe das políticas neoliberais, objetiva a redução do déficit fiscal, aplicando para tal o receituário do Consenso de Washington. Os cortes incidem sobre gastos sociais, seguidos de compulsiva venda de patrimônio público a preços desvalorizados. (STRECK; MORAIS 2010, p. 152-153)
\end{abstract}

Eis aqui o ponto nevrálgico da complexa mundialidade pós-moderna, que traz no seu imo a globalização neoliberal de neutralização axiológica da ConstituiçãoDirigente em prol de uma competição internacional neodarwinista acirrada entre 
centros mundiais de poder (EUA, China, União Europeia e Japão) e cuja materialização somente é possível com a mitigação ou até mesmo desconstrução total do Estado Democrático Social de Direito (welfare state) no âmbito dos países de modernidade tardia (nações subdesenvolvidas da periferia do sistema internacional).

Realmente, é indispensável captar o verdadeiro papel do Estado no mundo globalizado, mormente na periferia do sistema mundial do Sul Global, na qual os interesses estratégicos das grandes potências mundiais do Centro Global impõem mudanças na Constituição e nos marcos regulatórios da economia nacional. ${ }^{7}$

Isso deixa claro que o jogo geopolítico de poder mundial do Centro Global se projeta sobre as ordens internas do Sul Global, notadamente, dos países de modernidade tardia, o que logicamente obriga o estudioso dos direitos humanos a examinar as interferências jurídico-constitucionais advindas do projeto epistemológico neoliberal, implantado após a queda do Muro de Berlim e cujo foco passou a ser a redução jurídica do Estado e a desregulamentação do comércio global. Nesse sentido, Paulo Bonavides, com precisão acadêmica, mostra que:

O fato novo e surpreendente do modelo de globalização em curso é que ele
não opera nas relações internacionais com valores e princípios; sua
ideologia, aparentemente, é não ter ideologia, posto que esteja a mesma
subjacente, oculta e invisível no monstruoso fenômeno de poder e
subjugação, que é a maneira como a sociedade fechada e incógnita das
minorias privilegiadas, dos concentradores de capitais, faz a guerra de
escravização, conquistando mercados, sem disparar um só tiro de
canhão e sem espargir uma única gota de sangue. Desferem,
simplesmente, a pretexto de reformar, modernizar e globalizar a economia,
os sinistros golpes de Estado institucionais, tendo para tanto por
instrumentos e executores os governos títeres da "ditadura constitucional"
de que ora estamos sendo vítimas neste País. (BONAVIDES, 2009, p. 6-7,
grifo nosso).

Assim, é imperioso vislumbrar a globalização, tanto sob seu aspecto positivo de integração cultural de todos os povos da Terra, como, também, sob seu aspecto negativo de imposição do projeto epistemológico neoliberal, cujo símbolo máximo é a ideia de pensamento único do fim da História de Francis Fukuyama (FUKUYAMA, 1998). De fato, essa ideia-força de fim da História projeta a imagem de uma nova mundialidade sem guerras e de cooperação internacional benéfica para toda a

\footnotetext{
7 Observe, com atenção, que, muitas vezes, nem mesmo países, como o Brasil, situado entre as dez maiores economias do planeta, com latitude geopolítica de contribuir para a consolidação de uma ordem geopolítica multipolar, conseguem perceber ou enfrentar tais imposições externas.
} 
humanidade. Em essência, o fim da História de Fukuyama quer simbolizar a vitória do capitalismo e a repotencialização da doxa liberal. ${ }^{8}$

No plano da teoria constitucional, o movimento neoliberal apresenta forte crítica às concepções hermenêuticas de proteção de trabalhadores, que retiram a competitividade dos Estados nacionais no mercado internacional. Foi com tal tipo de retórica que a elite dominante da periferia do sistema mundial foi facilmente seduzida pelo projeto do capitalismo democrático neoliberal. Infelizmente, como bem destacou Bonavides, operou-se a guerra de escravização dos países subdesenvolvidos pela conquista de mercados sem disparar um só tiro de canhão e sem espargir uma única gota de sangue. Isso não é preciso, pois, não há nenhum tipo de reação. É o próprio Congresso Nacional que se encarregará de legislar em defesa dos interesses estratégicos dos países desenvolvidos em detrimento dos interesses nacionais.

Nesse diapasão, é muito triste perceber que os Parlamentos dos Países de modernidade tardia deixam de representar democraticamente o povo, passando a atuar como meros reprodutores de normas jurídicas feitas fora dos limites soberanos do Estado e fazendo valer a visão de Norberto Bobbio (2004), quando afirma que o poder real já não é mais o Parlamento, porque se transformou em mera câmara de ressonância de decisões políticas tomadas fora do seu âmbito. ${ }^{9}$

Com efeito, é melancólico constatar que o projeto epistemológico neoliberal, sem nenhuma necessidade de fazer uso da força militar (hard power) e sem nenhum tipo de derramamento de sangue, revelou-se eficaz e eficiente na imposição da força normativa dos mercados e seu consectário mais insensível, qual seja: a neutralização axiológica da Constituição Dirigente, retirando-Ihe a eficácia positiva ou social tão

\footnotetext{
${ }^{8}$ Em conseqüência, o constitucionalismo da pós-modernidade (aqui sendo por enquanto interpretado como o Estado Neoliberal de Direito) caracteriza-se por ser um movimento político-hermenêutico de forte crítica ao dirigismo constitucional da era moderna. Com rigor, salienta a emergência de um novo paradigma constitucional, próximo do arquétipo liberal e afastado do welfarismo constitucional. Apresenta-se com incredibilidade em relação às propostas sociais universalizantes do dirigismo constitucional, como aquela que justifica a intervenção estatal para a proteção dos hipossuficientes. A questão da intervenção estatal no domínio privado é tida agora como um jogo retórico de promessas inexequíveis que jamais atingirão a universalidade dos cidadãos.

9 Para Norberto Bobbio, o parlamento, na sociedade industrial avançada, não é mais o centro do poder real, mas apenas, frequentemente, uma câmara de ressonância de decisões tomadas em outro lugar. (BOBBIO, 2004, p. 159).
} 
arduamente conquistada, sob a justificativa de que se acentuava cada vez mais a crise do Estado Democrático Social de Direito.

E assim é que, sob as ruínas do Estado do Bem-Estar Social, já desponta um cenário tendencial voltado para uma nova realidade que Bolzan de Morais nomina de "neocapitalismo", vale defini-lo com as palavras do autor:

Um projeto vinculado ao viés econômico do liberalismo, onde, ao que se vê, há uma intenção não expressa de liberar o capital - e o capitalismo financeiro - das amarras que acabaram por se constituir através, entre outros, dos conteúdos liberais dos seus núcleos moral e político-jurídico. (BOLZAN, 2005, p. 17)

Portanto, com espeque na livre iniciativa e na autonomia da vontade como instrumentos realizadores da democracia e da liberdade política, o projeto neoliberal da pax americana procurou justificar eticamente a desconstrução dos direitos sociais e trabalhistas de segunda dimensão, tornando obsoleto o dirigismo constitucional, acusado de retrógrado e impróprio à competitividade internacional e à abertura mundial do comércio, exatamente num momento em que a globalização da economia exigia a desregulamentação dos mercados mundiais e a relativização do conceito de soberania.

No entanto, é neste contexto neoliberalizante de retomada do arquétipo constitucional pré-weimariano que se julga fundamental trazer de volta os direitos sociais fundamentais para a centralidade do constitucionalismo da pós-modernidade. Nas palavras de José Joaquim Gomes Canotilho:

Os direitos econômicos, sociais e culturais, na qualidade de direitos fundamentais, devem regressar ao espaço jurídico-constitucional e ser considerados como elementos constitucionais essenciais de uma comunidade jurídica bem ordenada. (CANOTILHO, 2004, p. 98)

Enfim, independentemente da aceitação ou não do fim da Guerra Fria como marco do surgimento de um constitucionalismo da pós-modernidade, o fato é que a queda do muro de Berlim gerou grandes transformações jurídicas no Estado Contemporâneo. Em nenhum dos três grandes paradigmas estatais da modernidade (Estado Absoluto-Estado Liberal e Estado Social), viveu-se a perspectiva de um cenário internacional unipolar, tal qual a tão propalada pax americana dos dias de hoje. 
O pensamento jurídico brasileiro não costuma investigar os elementos teóricos que informam essa perspectiva de unipolarismo geopolítico mundial e seus reflexos no campo jurídico-constitucional e, na sua esteira, no regime jurídico de proteção de direitos. Na doutrina pátria, um dos poucos autores que enfrentou o tema foi Daniel Sarmento, valendo, pois, reproduzir sua visão:

O colapso do comunismo, simbolizado pela queda do muro de Berlim, eliminou uma das ideologias rivais que se defrontavam e disputavam espaço num mundo até então bipolar. Com o fracasso retumbante da experiência marxista-leninista e o advento da Pax Americana, o capitalismo ficou mais a vontade para impor, agora sem concessões, o seu modelo econômico e social, que constituiria, segundo alguns, o 'fim da história'. Como se o fiasco do socialismo pudesse ofuscar os problemas crônicos do capitalismo, em especial a sua tendência para promover a desigualdade e aprofundar a exclusão social. (SARMENTO, 2002, p. 399)

Com a devida vênia, acredita-se que o eminente jurista se equivoca quanto ao conceito de pax americana ao identificá-la com o fim da história de Francis Fukuyama e, portanto, com a ideia de triunfo do capitalismo sobre o socialismo. Com rigor, a ideia de pax americana é um conceito geopolítico muito mais amplo, cujo significado é a imposição de um cenário internacional unipolar com predominância cêntrica norte-americana em todos os campos do poder nacional (político, econômico, militar, cultural e científico-tecnológico).

Realmente, por ser a única superpotência ainda remanescente, acredita-se que estamos vivendo sob os auspícios dessa Pax Americana. No entanto, a nosso juízo, acreditamos que tal interpretação é errônea, na medida em que os EUA não têm capital geopolítico suficiente para impor um cenário internacional unipolar, vale dizer, um quadro mundial onde não haja reação política, econômica, militar, cultural e tecnológica por parte das demais nações do mundo. O estabelecimento da Pax Americana seria sinônimo da natural envergadura dos EUA para reger unilateralmente as relações internacionais, o que evidentemente não parece ser verdadeiro. ${ }^{10}$

${ }^{10}$ Com a devida vênia, definitivamente, não se pode concordar com a ideia de que o Estado pósmoderno é uma nova concepção estatal regida pela supremacia absoluta de uma Pax Americana. Prefere-se optar pela construção acadêmica de que o Estado pós-moderno é, ao mesmo tempo, economicamente quadripolar (Estados Unidos, União Europeia, Japão e China), culturalmente multipolar (choque de civilizações huntingtoniano) e militarmente unipolar (supremacia norteamericana indiscutível). 
Observe, com atenção, que, diante de todo esse quadro conjuntural, sofistica-se a tarefa do jurista contemporâneo, uma vez que não lhe é mais facultado desconsiderar variáveis metajurídicas (notadamente geopolíticas) na complexa equação dogmática do direito contemporâneo. Seu campo de atuação transcende a esfera do jurídico e da letra da lei, para penetrar na esfera multidisciplinar circunscritiva da força normativa da geopolítica mundial. Já não lhe é dado mais permanecer alheio aos fatos geopoliticamente relevantes no mundo globalizado.

Trata-se de conhecer a realidade do mundo dos fatos, abrindo-se o debate para a questão da influência recíproca entre direito e geopolítica. É induvidoso, portanto, que novos conceitos, tais como geodireito, constitucionalismo estratégico e judicialização da geopolítica sejam incorporados na equação epistemológica do jurista hodierno.

A resposta constitucionalmente adequada só merecerá tal designação quando fruto de uma análise multidisciplinar, que se caracteriza pela decisão judicial tomada com apoio em avançadas teorias da geopolítica mundial. Com tal tipo de intelecção em mente, é possível buscar o aperfeiçoamento da proteção jurídica de direitos humanos, que deve se mover na direção de um marco legal mais sofisticado e que seja capaz de captar a conexão científica existente entre a geopolítica mundial e a proteção metaconstitucional de direitos humanos no âmbito de um verdadeiro Estado Democrático de Direito.

Em consequência, urge conceber uma nova teoria metaconstitucional dos direitos humanos, que seja edificada, a um só tempo, tanto na ascensão normativa das normas internacionais e do controle de convencionalidade, quanto na superação da ordem unipolar de pax americana. Eis aqui a essência da ordem metaconstitucional de direitos humanos: superação do mundo americano de imposição hegemônica (hard power), que deve ceder seu lugar para uma nova mundialidade cosmopolita, calcada no equilíbrio multipolar do poder mundial (soft power).

Agora, a normatividade dos direitos humanos cosmopolitas não se atrela tão somente ao conteúdo da norma constitucional posta (legislador democrático nacional), mas, também, ao grau de aceitabilidade que a norma metaconstitucional (legislador dos sistemas universal e regionais de proteção) atinge no ambito de 
juízes e tribunais de direito interno. É por tudo isso que importa examinar a seguir a transição geopolítica da pax americana para uma ordem mundial multipolar, cujo perfil se coaduna mais facilmente com a ideia-força de uma ordem metaconstitucional de direitos humanos.

\section{ESTADO METACONSTITUCIONAL DE DIREITO E ORDEM MUNDIAL MULTIPOLAR (MUNDO PÓS-AMERICANO)}

A presente segmentação temática propõe uma nova leitura acerca do regime de proteção dos direitos humanos, decorrente de duas grandes perspectivas que se apresentam ao constitucionalismo da pós-modernidade, quais sejam, o Estado Neoliberal de Direito e o Estado Metaconstitucional de Direito.

Ou seja, a linha epistêmico-conceitual aqui proposta tem a finalidade de examinar a dicotomia que se apresenta ao Estado Neoconstitucional de Direito que navega entre dois mares distintos. De um lado, o Estado Neoliberal de Direito e a sua tentativa de neutralização axiológica da Constituição Dirigente Welfarista a partir da mitigação dos direitos sociais de segunda dimensão e, do outro, o Estado Metaconstitucional de Direito, cuja dinâmica é calcada no regime jurídico de proteção dos direitos humanos de curso universal.

Ora, tanto a proteção constitucional assegurada pelo Estado nacional soberano, quanto a proteção global prevista nas Convenções Internacionais de Direitos Humanos, constituem o regime jurídico de tutela do cidadão cosmopolita. Colima-se, portanto, nessa segmentação temática, analisar a correspondência biunívoca existente entre o sistema jurídico de proteção dos direitos humanos e a ordem geopolítica mundial.

Ou seja, em termos simples, existe um vínculo que coloca o Estado Neoliberal de Direito e a proteção de direitos civis e políticos em contato com a ordem mundial unipolar de pax americana (mundo americano). Da mesma forma, existe um elo forte entre o Estado Metaconstitucional de Direito e a proteção de direitos cosmopolitas de curso universal e a ordem mundial multipolar (mundo pósamericano).

Com rigor, a doutrina pátria não costuma investigar tais linhas paralelas que colocam, lado a lado, a trajetória ascensional da ordem geopolítica mundial (ordem 
bipolar, pax americana e ordem multipolar) e as fases de evolução dos direitos humanos (direitos pré-históricos, direitos constitucionalizados e direitos cosmopolitas). ${ }^{11}$

Na linha do tempo, o constitucionalismo pós-moderno surge após 1989, onde se depara com a crise do "welfarismo constitucional", a globalização da economia, o projeto hegemônico neoliberal e a neutralização axiológica da segunda dimensão de direitos fundamentais, aí incluída a proteção dos trabalhadores e hipossuficentes. Essa é a perspectiva de implantação do Estado Neoliberal de Direito, antítese do Estado Metaconstitucional de Direito. ${ }^{12}$

Como já amplamente examinado, o constitucionalismo da modernidade tem duas grandes vertentes, a saber: o constitucionalismo garantista do Estado Liberal de Direito e o constitucionalismo dirigente do Estado Democrático Social de Direito. Em ambas vertentes, o regime jurídico de proteção dos direitos fundamentais dá-se dentro das fronteiras do Estado nacional soberano.

Em termos simples, é certo afirmar que a fase de constitucionalização dos direitos fundamentais vivenciou dois grandes ciclos democráticos, a saber: o Estado Liberal de Direito e o Estado Democrático Social de Direito. Tais ciclos democráticos perfazem a modernidade dos direitos fundamentais.

Já o constitucionalismo da pós-modernidade está vinculado à fase metaconstitucional, modelo ainda em construção, mais que já projeta a proteção dos direitos humanos para além das fronteiras nacionais. Será o fim de um mundo geopoliticamente unipolar e, na sua esteira, o fim de um direito internacional hegemônico caracterizado pelo sistema yaltiano de poder que marcará o nascimento do constitucionalismo da pós-modernidade, aqui caracterizado como a busca da constitucionalização transnacional dos direitos humanos, ou seja, trata-se de

\footnotetext{
${ }^{11}$ Realmente, esta temática ainda não mereceu, no Brasil, um tratamento sistemático pela doutrina, o que evidentemente dificulta a análise da classificação das diferentes fases de evolução que marcam a proteção dos direitos humanos ao longo da História, desde a antiguidade clássica até os dias atuais. A ideia aqui é ir para além dessa proteção nacional dos direitos humanos (constitucionalismo democrático ocidental) com o objetivo de examinar a visão pós-moderna dos direitos humanos, operando-se a vinculação entre o Estado Metaconstitucional de Direito e a proteção transnacional dos direitos humanos (transconstitucionalismo do Estado pós-moderno).

12 Portanto, para compreender o estado da arte do regime de proteção dos direitos humanos é necessário compreender toda a fase moderna de constitucionalização dos direitos fundamentais. Não se pode confundir o constitucionalismo da modernidade (fase de constitucionalização dos direitos fundamentais e suas etapas liberal e social) com o constitucionalismo da pós-modernidade (fase de metaconstitucionalização dos direitos humanos).
} 
um projeto epistemológico de direito cosmopolítico que substitui os projetos do liberalismo e do socialismo.

Assim sendo, a fase de constitucionalização transnacional aspira consolidar um novo ciclo democrático, agora dito democracia pós-moderna ou democracia cosmopolita, cujo empuxo arquimediano é a implantação de uma Ordem Mundial Multipolar, calcada no equilíbrio geopolítico de poder, sem predominância cêntrica de nenhum Estado ou coligação de Estados. ${ }^{13}$

Com efeito, opera-se aqui revolução profunda no ideal de proteção de direitos, sobre o qual se assenta a ordem metaconstitucional de direitos humanos. Não se pretende, neste momento, tratar de todas as características do metaconstitucionalismo pós-moderno, mas, tão somente, destacar sua relevância para o estudo dos direitos humanos na contemporaneidade, uma vez que simboliza a supremacia de tais direitos sobre o próprio Estado, superando, pois, a ideia de impenetrabilidade kelseniana da ordem jurídica soberana nacional.

Para bem compreender tal transição, é preciso reconhecer que os direitos humanos são direitos históricos, que evoluem de acordo com as limitações e obrigações que são impostas ao Estado em prol da proteção do indivíduo perante esse mesmo Estado, ou seja, o reconhecimento de que a proteção dos direitos humanos é gradual e em constante mutação. Como bem mostra Bobbio na sua obra "A era dos direitos":

Do ponto de vista teórico, sempre defendi - e continuo a defender, fortalecido por novos argumentos - que os direitos do homem, por mais fundamentais que sejam, são direitos históricos, ou seja, nascidos em certas circunstâncias, caracterizadas por lutas em defesa de novas liberdades contra velhos poderes, e nascidos de modo gradual, não todos de uma vez e nem de uma vez por todas. (BOBBIO, 2004, p. 25)

Para o eminente autor, os filósofos são convocados a dar seu parecer sobre um fundamento dos direitos do homem que seja absoluto, irresistível, inquestionável, o que parece ser um problema mal formulado, pois:

\footnotetext{
13 No entanto, sem nenhum tipo de zotismo acadêmico, há que se reconhecer que o projeto epistemológico metaconstitucional kantiano encontra grande resistência advinda do seu principal opositor, qual seja, o projeto epistemológico neoliberal da Pax Americana. O ponto de inflexão entre a modernidade e a pós-modernidade é aqui vislumbrado como sendo a passagem de um mundo unipolar norte-americano para um mundo multipolar de equilíbrio geopolítico.
} 


\begin{abstract}
A liberdade religiosa é um efeito das guerras de religião; as liberdades civis, da luta dos parlamentos contra soberanos absolutos; a liberdade política e as liberdades sociais, do nascimento, crescimento e amadurecimento do movimento dos trabalhadores assalariados, dos camponeses com pouca ou nenhuma terra, dos pobres que exigem dos poderes públicos não só o reconhecimento da liberdade pessoal e das liberdades negativas, mas também a proteção do trabalho contra o desemprego, os primeiros rudimentos de instrução contra o analfabetismo, depois a assistência para a invalidez e a velhice, todas elas carecimentos que os ricos proprietários podiam satisfazer por si mesmos. (BOBBIO, 2004, p. 25)
\end{abstract}

Nesse sentido, perfeita a intelecção de Norberto Bobbio, demonstrando a trajetória de evolução dos regimes de proteção dos direitos humanos, desde a garantia da liberdade religiosa somente alcançada a partir da Paz de Vestfália de 1648 (formação do Estado absoluto), perpassando pelo respeito às liberdades civis resultantes da luta dos parlamentos contra soberanos absolutos (formação do Estado Liberal de Direito) até, finalmente, chegar-se às liberdades sociais resultantes do movimento dos trabalhadores assalariados, dos camponeses com pouca ou nenhuma terra, dos pobres, dos hipossuficientes, contra o analfabetismo e da assistência para a invalidez, velhice e infância (Estado Democrático Social de Direito).

Observe, aqui, com atenção, a importância dessas fases de evolução do constitucionalismo da modernidade, cujo âmbito de incidência ainda se encontra dentro dos limites territoriais de um Estado nacional soberano.

Diferente é a estrutura do novo paradigma de metaconstitucionalização dos direitos humanos, que transcende as fronteiras nacionais. Eis aqui o ponto central do presente estudo: compreender que, a partir da metaconstitucionalização, opera-se a transformação mais radicalizante da concepção jurídica de proteção dos direitos humanos, qual seja a transposição do constitucionalismo democrático e a inauguração do transconstitucionalismo de inspiração kantiana.

O que agora importa é examinar a proteção supranacional dos direitos humanos, reduzindo o campo de atuação do Estado soberano, quer seja pela autolimitação dos Estados soberanos com relação às normas jus cogens de direito internacional, quer seja pela positivação de normas cosmopolitas que se sobrelevam sobre o próprio Estado.

A finalidade do paradigma democrático metaconstitucional é a garantia dos direitos humanos em escala planetária. Sua pretensão metodológica é a consecução 
de normas cosmopolitas que vinculem por intermédio do respeito dos Estados soberanos aos direitos humanos. É nesta trilha que a fase metaconstitucional dos direitos humanos cosmopolitas surge em substituição à fase moderna de constitucionalização de direitos fundamentais de um determinado Estado nacional.

Ontem, a fase moderna de constitucionalização dos direitos fundamentais e seus dois grandes ciclos democráticos: Estado Liberal de Direito e Estado Democrático Social de Direito. ${ }^{14}$ Hoje, a fase pós-moderna, na qual se vive a esperança de implantação da fase metaconstitucional dos direitos humanos.

Como já amplamente dito, a ordem metaconstitucional de direitos humanos ainda se encontra em construção, sendo certo afirmar, entretanto, que representa o estado da arte na proteção dos direitos cosmopolitas, na medida em que projeta a ideia-força de um Estado Universal de Direito de inspiração kantiana, que não se submete às vontades nacionais soberanas. $\mathrm{O}$ indivíduo ganha proteção supranacional contra as violações do seu próprio Estado nacional.

Consequentemente, a metaconstitucionalização de direitos, ao constituir exigências do Estado Universal de Direito, permite a consolidação de um novo ciclo democrático, agora dito pós-moderno de cidadania cosmopolita. É importante compreender, com clareza, que o projeto epistemológico metaconstitucional, de viés kantiano, encontra no controle de convencionalidade um dos seus grandes pilares de sustentabilidade.

Certamente a proteção metaconstitucional de direitos é uma grande expectativa e perspectiva dogmática, notadamente pelo avanço que representa quando se considera os tratados internacionais já ratificados na História da humanidade, daí seu potencial no âmbito do projeto cosmopolita de constitucionalização transnacional dos direitos humanos. Com efeito, a proposta central da ordem metaconstitucional de direitos humanos, que se expressa do ponto de vista jurídico-hermenêutico pelos núcleos normativos representados pela garantia dos tratados internacionais de direitos humanos (notadamente a proteção à infância, à mulher, à velhice, à pessoa com deficiência etc.), é estabelecer um sistema ideal a ser instrumentalizado através da cidadania cosmopolita, que é complexa e de difícil

${ }^{14}$ Tais ciclos democráticos perfazem a modernidade dos direitos fundamentais. 
exequibilidade, pois pretende deslocar a proteção jurídica para o âmbito universal em detrimento da forma nacional soberana.

Busca-se, aqui, nesta última fase, a construção de uma ordem internacional democrática cosmopolita. É por tudo isso que se entende que o grande desafio do Estado Neoconstitucional de Direito é refutar a consolidação do Estado Neoliberal de Direito, colocando em seu lugar o Estado Metaconstitucional de Direito.

Vicente Barretto mostra com precisão que "o conceito de direito cosmopolita, proposto por Kant, refere-se, principalmente, ao entendimento de que a evolução histórica, e com ela as luzes da razão, iriam encontrar ou formular normas de fundamentação ética, que poderiam ser consideradas como uma forma de direito". (BARRETO, 2002, p. 385).

Um dos postulados essenciais em que se funda o metaconstitucionalismo é a racionalidade universalizante, na qual os valores a serem protegidos são livremente aceitos por todos os homens, independentemente de nacionalidade, cultura, etnia ou religião. Segundo tal paradigma, há uma única ordem jurídica, cujos valores são compartilhados pela comunidade cosmopolita. Enfim, essa é a essência da ordem metaconstitucional de direitos humanos.

Por outro lado, há que se reconhecer que os alicerces do Estado Metaconstitucional de Direito se equilibram sobre um conjunto frágil de realidades vinculantes, como, por exemplo, a ideia-força da construção de um Estado Universal de Direito, no qual a violação de um direito fundamental em determinada região pobre da África ou da América Latina repercutirá igualmente em todas as demais nações do Planeta. É claro que tal perspectiva ainda não se encontra no horizonte visível da sociedade internacional atual, no entanto, o que é importante compreender é que uma ordem civilizatória metaconstitucional pressupõe a consolidação de um Estado Universal de Direito dessa natureza.

Além disso, uma ordem metaconstitucional de direitos humanos pressupõe um plexo de realidades vinculantes em todas as expressões do poder nacional. Isto significa dizer, por exemplo, que, geopoliticamente, seu motor é a implantação de uma ordem mundial multipolar, sem predominância cêntrica de um único poder global ou aliança de poderes prontos para exercer a liderança mundial a seu talante. 
Com a devida agudeza de espírito, o leitor deve compreender que esta realidade vinculante demonstra que a ordem mundial pós-moderna, no campo da geopolítica, se encontra em transição de uma ordem unipolar de hegemonia norte-americana para uma ordem multipolar de equilíbrio global, mais afeita às perspectivas do Estado Metaconstitucional de Direito.

Com isso, começa a aparecer no horizonte da agenda mundial, a ideia kantiana de projetar justiça além fronteiras, sob a égide de uma sociedade internacional de Estados Democráticos de Direito de cidadania cosmopolita. Proclama-se, no âmbito do paradigma metaconstitucional dos direitos humanos, a pós-modernidade axiológica, na qual o regime jurídico protetivo de direitos caminha no trilho da ética universal.

É a virada kantiana privilegiando a dimensão ética universal das normas jurídicas e homenageando iniciativas de proteção ao núcleo intangível de dignidade humana dos hipossuficientes em escala planetária.

\section{CONCLUSÃO}

O presente trabalho procurou analisar as perspectivas de implantação da ordem metaconstitucional de direitos humanos no âmbito do constitucionalismo da pós-modernidade. Certamente tal perspectiva metaconstitucional simboliza o mais avançado grau de dogmática protetiva de direitos, podendo-se mesmo afirmar que sua implementação seria equivalente à instauração do quase utópico Estado Universal de Direito.

Em linhas gerais, pode-se afirmar que a evolução dos direitos humanos não pode ficar apartada da fase metaconstitucional, paradigma ainda em construção, mas que tenta impulsionar o direito constitucional pós-moderno na direção desse Estado Universal de Direito e da democracia cosmopolita.

Neste mister precípuo, um dos aspectos mais importantes que se precisa destacar é a questão do diálogo epistemológico entre a ordem metaconstitucional de direitos humanos e a ordem geopolítica multipolar.

Na linha epistêmico-conceitual, o Estado Metaconstitucional de Direito ganha relevância transcendental, na medida em que a ética e o direito irão se encontrar na 
realização da vida digna para todos os cidadãos do planeta, independentemente da sua nacionalidade ou do catálogo jusfundamental do seu Estado de origem. Isto significa dizer que a força normativa do direito cosmopolítico kantiano não dimana de normas feitas internamente por Estados soberanos, mas, sim, das normas metaconstitucionais cosmopolitas de curso universal. ${ }^{15}$

Com tal tipo de intelecção em mente, é possível identificar os óbices que se apresentam à ordem metaconstitucional de direitos humanos, desde um ponto de vista de relação de poder hegemônico em escala planetária, senão vejamos: no mundo de Pax Americana, a violação de um direito fundamental, cometida em determinado País que seja aliado estratégico dos EUA, certamente, não repercutirá no resto do mundo. Já a violação de um direito fundamental, cometida em País que resista, desafie ou se oponha aos EUA, induvidosamente, repercutirá intensamente em todos os demais Estados da sociedade internacional. Ora isso representa exatamente a antítese da ordem metaconstitucional de direitos humanos.

Portanto, em tempos de estatalidade pós-moderna, um dos grandes desafios do Estado Democrático de Direito é deslocar para a centralidade do regime jurídico de proteção dos direitos humanos o diálogo epistemológico entre o controle de constitucionalidade e o controle de convencionalidade. Com efeito, a evolução do pensamento jurídico contemporâneo perpassa necessariamente pela conexão entre essas duas ordens jurídicas: a dimensão interna (máxime com a ideia de supremacia da Constituição) e a dimensão metaconstitucional (máxime com a consolidação dos tratados internacionais sobre direitos humanos).

Observe, com atenção, que a fase metaconstitucional de direitos simboliza a vitória do constitucionalismo democrático e do Estado Democrático de Direito. A questão não é de enfraquecimento da soberania nacional, mas, sim, de implantação de uma nova fórmula de proteção jurídica para o cidadão comum,

\footnotetext{
${ }^{15}$ Em tempos de estatalidade pós-moderna, um dos grandes desafios do Estado Democrático de Direito é deslocar para a centralidade do regime jurídico de proteção dos direitos humanos o paradigma metaconstitucional e o controle de convencionalidade. Com efeito, a evolução do pensamento jurídico contemporâneo perpassa necessariamente pela conexão entre essas duas ordens jurídicas: a dimensão interna (máxime com a ideia de supremacia da Constituição) e a dimensão metaconstitucional (máxime com a consolidação dos tratados internacionais sobre direitos humanos).
} 
independentemente da sua nacionalidade. ${ }^{16}$ É nesse diapasão que o constitucionalismopréweimariano/neoliberal/garantista/absenteísta/minimalista/negat ivista não se coaduna com a tese da força axiológico-normativa da proteção universal dos direitos humanos, cuja dinâmica estabelece que a violação de direitos deve repercutir igualmente em todos os lugares da Terra.

Urge, pois, equilibrar as principais tendências epistemológicas do constitucionalismo da pós-modernidade, quais sejam: de um lado, o Estado Neoliberal de Direito e o retorno ao arquétipo constitucional pré-weimariano de índole minimalista lockeana e, do outro, o Estado Metaconstitucional de Direito e a implantação do arquétipo cosmopolita de inspiração universalista kantiana.

Sem desbordar dos limites impostos pela busca da dignidade da pessoa humana, o projeto kantiano de constitucionalização universal deve ser capaz de disciplinar as regras de um direito cosmopolítico calcado na ética universal.

\section{REFERÊNCIAS}

BARRETTO, Vicente de Paulo. O fetiche dos Direitos Humanos e outros temas. Rio de Janeiro: Lumen Juris, 2010.

BARRETTO, Vicente de Paulo. Bioética, biodireito e direitos humanos. In: TORRES, Ricardo Lobo (Org.). Teoria dos direitos Fundamentais. Rio de Janeiro: Renovar, 2002. p. 383-424.

BARROSO, Luís Roberto. Fundamentos Teóricos e Filosóficos do Novo Direito Constitucional Brasileiro (Pós-modernidade, teoria crítica e pós-positivismo). In: BARROSO, Luís Roberto (Org). A nova interpretação constitucional. Ponderação, Direitos fundamentais e Relações Privadas. Rio de Janeiro: Renovar, 2003.

BOBBIO, Norberto. A era dos direitos. Tradução de Carlos Nelson Coutinho. Rio de Janeiro: Elsevier, 2004.

BOLZAN DE MORAIS, José Luis. As crises do Estado. In: MORAIS, José Luis Bolzan de (Org.). $O$ Estado e suas crises. Porto Alegre: Livraria do Advogado, 2005.

\footnotetext{
${ }^{16}$ Assim sendo, o estudioso dos direitos humanos tem a missão exegética de desvelar os princípios fundantes do metaconstitucionalismo, notadamente aqueles focados na proteção da dignidade da pessoa humana dos hipossuficientes em âmbito mundial. Ora a ordem neoliberal do capitalismo democrático ocidental, agora reforçada pelo capitalismo de estado chinês, não projeta nenhuma perspectiva de garantia de direitos, ao revés, projeta sim a imagem de um quadro de miserabilidade humana ao redor do Planeta.
} 
BONAVIDES, Paulo. Do país constitucional ao país neocolonial: a derrubada da constituição e a recolonização pelo golpe de estado institucional. 4. ed. São Paulo: Malheiros, 2009.

CANOTILHO, José Joaquim Gomes. Estudos sobre direitos fundamentais. Coimbra: Coimbra Editora, 2004.

FUKUYAMA, Francis. 0 fim da História. Rio de Janeiro: Biblioteca do Exército, 1998.

SARMENTO, Daniel. Os direitos fundamentais nos paradigmas liberal, social e póssocial-(pós-modernidade constitucional?). In: FERRAZ JR., Tércio Sampaio (Coord.). Crises e desafios da Constituição brasileira. Rio de Janeiro, 2002, p. 399.

STRECK, Lenio Luiz; MORAIS, José Luis Bolzan de. Ciência política \& teoria do estado. Porto Alegre: Livraria do Advogado, 2010.

\section{OBRAS CONSULTADAS}

BARROSO, Luís Roberto. A reconstrução democrática do direito público no Brasil. Rio de Janeiro: Renovar, 2007.

BARROSO, Luís Roberto. O começo da história: a nova interpretação constitucional e o papel dos princípios no direito brasileiro. In: BARROSO, Luís Roberto. Temas de Direito Constitucional. Rio de Janeiro, Renovar, 2005. Tomo 3.

BOBBIO, Norberto. 0 positivismo jurídico: lições de filosofia do direito. Tradução de Márcio Pugliesi, Edson Bini e Carlos E. Rodrigues. São Paulo: Ícone, 1995.

HABERMAS, Jürgen. Direito e democracia: entre facticidade e validade. Tradução Flávio Beno Siebeneichler. 2. ed. Rio de Janeiro: Tempo Brasileiro, 2003.

LASSALE, Ferdinand. 0 que é uma constituição? 2. ed. Campinas: Minelli, 2005.

LOUGHLIN, Martin. Sword \& scales: an examination of the relationship between law \& politics. Oxford, Porland Oregon: Hart publishing, 2000.

PIOVESAN, Flávia. Direitos humanos e justiça internacional: um estudo comparativo dos sistemas regionais europeu, interamericano e africano. 2. ed. São Paulo: Saraiva, 2013.

RAWLS, John. Uma teoria da justiça. Brasília: Universidade de Brasília, 1981.

SARLET, Ingo Wolfgang. A eficácia dos direitos fundamentais: uma teoria geral dos direitos fundamentais na perspectiva constitucional. Porto Alegre: Livraria do Advogado, 2009. 